\title{
Strawberry polyphenols are equally cytotoxic to tumourigenic and normal human breast and prostate cell lines
}

\author{
JENNIFER WEAVER ${ }^{1}$, TINA BRISCOE ${ }^{1}$, MIMI HOU ${ }^{1}$, CHRIS GOODMAN $^{2}$, SLAWOMIR KATA $^{2}$, \\ HEATHER ROSS ${ }^{3}$, GORDON McDOUGALL $^{3}$, DEREK STEWART ${ }^{3}$ and ANDREW RICHES ${ }^{1}$ \\ ${ }^{1}$ Bute Medical School, University of St. Andrews, St. Andrews; ${ }^{2}$ Department of Urology, \\ University of Dundee, Dundee; ${ }^{3}$ The Scottish Crop Research Institute, Invergowrie, Dundee, UK
}

Received October 2, 2008; Accepted November 24, 2008

DOI: 10.3892/ijo_00000203

\begin{abstract}
The cytotoxic effects of strawberry polyphenols were investigated on normal cells and tumour cells derived from the same patient. A human prostate epithelial cell line (P21) and two tumour cell lines (P21 tumour cell line 1 and 2) derived from the same patient, and a normal human breast epithelial cell line (B42) and a tumour line derived from it (B42 clone 16) were used. A polyphenol-rich extract derived from strawberry or anthocyanin or tannin-rich sub-fractions were applied to the cell lines in doses varying from 50 to $1.5 \mu \mathrm{g} / \mathrm{ml}$. The strawberry extract was cytotoxic with doses of $\sim 5 \mu \mathrm{g} / \mathrm{ml}$ causing a $50 \%$ reduction in cell survival in both the normal and the tumour lines. The extracts were also cytotoxic to peripheral blood human lymphocytes stimulated with phytohaemagglutinin but higher levels $(>20 \mu \mathrm{g} / \mathrm{ml}$ for $50 \%$ reduction in cell survival) were required. After fractionation of the strawberry sample, the cytotoxicity was retained in the tannin-rich fraction and this fraction was considerably more toxic to all cells (normal or tumour cell lines or lymphocytes) than the anthocyanin-rich fraction. Established prostate (LNCaP and PC-3) and breast (MCF-7) tumour cell lines were more resistant to the strawberry extract with concentrations of $50 \mu \mathrm{g} / \mathrm{ml}$ required for $50 \%$ reduction in cell survival, which is similar to levels in previous studies on the antiproliferative effects of berry extracts. Although these concentrations are much greater than possible physiological levels, they are comparable to those reported in other studies. From these findings, we conclude that there is little evidence to assume that polyphenols from strawberry have a differential cytotoxic effect on tumour cells relative to comparable normal cells from the same tissue derived from the same patient.
\end{abstract}

Correspondence to: Professor Andrew Riches, Bute Medical School, Bute Medical Building, University of St. Andrews, St. Andrews KY16 9TS, Scotland, UK

E-mail: acr1@st-andrews.ac.uk

Key words: cancer, cytotoxicity, polyphenols, anthocyanins, tannins, prostate, breast

\section{Introduction}

The epidemiological evidence for an association between the consumption of fruit and vegetables and a reduced risk of human diseases, such as cardiovascular disease and cancer is strong (1-4). As would be expected, researchers have attempted to identify components of fruit and vegetables with anti-cancer effects (5). Fruit and vegetables contain an incredible diversity of phytochemicals, many of which are potent antioxidants capable of scavenging oxygenated free radicals which can damage cellular components such as DNA, proteins or membrane lipids (6). Control of this oxidative damage has been hypothesised to influence the onset of carcinogenesis $(5,7,8)$. Unregulated cell proliferation and reduced apoptosis are characteristic of the initiation and progression of cancers (8). Many studies have confirmed that berry extracts rich in a diversity of polyphenol antioxidants inhibit proliferation of cancer cells in vitro (9-11).

Although some workers have carried out studies in genetically-predisposed mice $(12,13)$ or other animal models (14) and intervention trials of black raspberries against human esophageal and colon cancer (15) are in progress, much of the evidence for cytotoxic effects of berry components have come from studies on proliferation of established cultured cancer cells such as leukemic HL60 cells (16), colon Caco-2 cells $(17,18)$ and liver HepG2 cells $(19)$. However, few studies have compared the effect of these compounds on normal cells.

Many studies have shown that berry components have anti-proliferative effects on cultured cancer cell lines. In a number of comparative studies with 'normal' cell lines some researchers have suggested that berry components may be selectively cytotoxic against cancer cells. Black raspberry extracts exerted a distinct differential effect on pre-malignant and malignant oral epithelial cells as compared to normal human oral epithelial cells at doses of $100-200 \mu \mathrm{g} / \mathrm{ml}(20)$. Cocoa extracts had a differential effect on prostate cancer cell lines DU145 and 22Rv1 compared to a normal prostate epithelial cell line (21). Red wine polyphenols were reported to have selective cytotoxicity against human breast cancer cells over normal cell lines (22). Studies on the responses of colon cancer and normal gastric mucosal cells to gallotannin and proanthocyanidin extracts $(11,23)$ indicated that they have 
differential cytotoxic effects and proanthocyanidins enhanced the growth of the normal gastric mucosal cells (11).

However, these normal cell lines are rarely derived from the same patient as the cancer cell lines and as we know that susceptibility of cancer cell lines derived from different tissues (i.e. breast, lung, colon and prostate) to berry components can differ markedly (24), it is certainly possible that differences in cytotoxicity between the normal cells and cancer cells may be due to physiological differences related to their originating tissue.

In this study, we focused on the effects of polyphenol-rich extracts of strawberry on normal human prostate and breast epithelial cells and cancer cells derived from them in vitro. We also report on the responses of human peripheral blood lymphocytes.

\section{Materials and methods}

Fruit collection and purification of strawberry extract. Strawberries (Fragaria ananassa c.v. Elsanta) were obtained from farmers local to the Scottish Crop Research Institute. A polyphenol-rich extract devoid of free sugars, organic acids and vitamin C, was obtained as detailed previously (25). Briefly, frozen fruit was homogenised in a Waring blender using an equal volume to weight of $0.2 \%(\mathrm{v} / \mathrm{v})$ acetic acid in water. The extract was filtered through a glass sinter and applied to $\mathrm{C} 18$ solid phase extraction units (Strata C18-E, GIGA units, Phenomenex Ltd., UK) pre-washed in $0.2 \%$ $(\mathrm{v} / \mathrm{v})$ acetic acid in acetonitrile then equilibrated in $0.2 \%(\mathrm{v} / \mathrm{v})$ acetic acid in water. Unbound material, which contained the free sugars, organic acids and vitamin C, was discarded. After extensive washes with water, the polyphenol-enriched bound extracts (SPE -bound) were eluted with acetonitrile.

A portion of the SPE-bound sample was dried by evaporation and dissolved in 50\% (v/v) ethanol then applied to a column of Sephadex LH-20 prepared in 50\% (v/v) ethanol/ water then $50 \%(\mathrm{v} / \mathrm{v})$ acetone/water before being equilibrated with three volumes of $50 \%$ ethanol. The run-through plus a column volume of $50 \%$ ethanol collected as the unbound fraction. This red material obviously contained the bulk of the anthocyanins. The column was washed with three column volumes of $50 \%$ ethanol. The bound fraction was eluted with three volumes of $50 \%$ acetone. The unbound and bound fraction were evaporated to near dryness then stored frozen.

Anthocyanin and phenol assays. The total anthocyanin concentration was estimated by a $\mathrm{pH}$ differential absorbance method (26). The absorbance value was related to anthocyanin content using the molar extinction coefficient calculated in-house for cyanidin-3-O-glucoside (purchased from ExtraSynthese Ltd., Genay, France). Phenol content was measured using a modified Folin-Ciocalteau method (27). Phenol contents were estimated from a standard curve of gallic acid. Aliquots of fractions containing $500 \mu \mathrm{g}$ of phenols as gallic acid equivalents (GAE) were dried using a Speed-Vac centrifugal evaporator (Thermo-Finnegan Ltd.).

Vials of extracts were defrosted as required. Prior to adding to cells, $500 \mu 1$ of sterile PBS was pipetted into vials and passed through the pipette tip many times to dissolve the extract. The extract was passed through a $0.22-\mu \mathrm{m}$ filter to produce sterile extract and the phenol concentration was checked. The sterile filtrate was diluted to produce solutions from 500 to $1 \mu \mathrm{g} / \mathrm{ml} \mathrm{GAE}$.

Liquid chromatography mass spectrometry (LC-MS) analysis. Samples containing $20 \mu \mathrm{g}$ phenols (GAE) were analysed on a LCQ-Deca system, comprising Surveyor autosampler, pump and photo diode array detector (PDAD) and a ThermoFinnigan mass spectrometer iontrap. The PDAD scanned discrete channels at 280, 365 and $520 \mathrm{~nm}$. The samples were applied to a C-18 column (Synergi Hydro C18 with polar end-capping, 4.6x $150 \mathrm{~mm}$, Phenomonex Ltd., UK) and eluted over a gradient of $5 \%$ acetonitrile $(0.1 \%$ formic acid) to $30 \%$ acetonitrile $(0.1 \%$ formic acid) $>60 \mathrm{~min}$ at a rate of $400 \mu \mathrm{l} / \mathrm{min}$. The LCQ-Deca LC-MS was fitted with an ESI (electrospray ionisation) interface and analysed the samples in positive and negative ion mode. There were two scan events; full scan analysis followed by data-dependent MS/MS of most intense ions using collision energies (source voltage) of $45 \%$. The capillary temperature was set at $250^{\circ} \mathrm{C}$, with sheath gas at 60 psi and auxiliary gas at 15 psi.

Cell culture. Transurethral resected (TUR) prostate tissue samples, obtained from patients being treated for benign prostatic hyperplasia following ethical approval (LREC 191/01), were treated with collagenase (Type 1 Sigma C0130 $4000 \mathrm{U} / \mathrm{ml}$ ) and grown in culture until outgrowths of monolayer prostate epithelial cells were seen. The cells were transduced with two constructs (CDK4 and hTERT) and the cell lines were propagated in culture (28). A normal human prostate epithelial cell line (P21) was established and two cloned prostate tumour cell lines were cloned from the same patient. One was established from a region containing tumour cells (P21 prostate tumour cell line 1) and another following exposure of the P21 line to $\gamma$-irradiation (P21 prostate tumour cell line 2) (29).

Primary cultures of human mammary epithelial cells (HMEC) were established from surgically removed tissue samples from regions remote from the tumour in a patient with breast cancer presenting for mastectomy (30). The cells were grown in mammary epithelial cell medium (MEBM) with additives (Lonza). Immortalised cell lines were then generated by transduction using the human telomerase catalytic subunit (hTERT). A cloned cell line B42 was established following selection with puromycin. The B42 cell line was exposed to 20 fractions of 2 Gy $\gamma$-irradiation and screened for anchorageindependent growth in soft agar. The parent line B42 does not produce significant numbers of anchorage-independent colonies whereas the irradiated line does produce significant numbers of colonies. Colonies were picked from the $0.3 \%$ agar and an irradiated cloned cell line established (B42 clone 16).

Prostate cell lines were cultured in PrEBM with the additives supplied (Lonza). Breast cell lines were cultured in MEBM with the additives supplied (Lonza). Cells were cultured at $37^{\circ} \mathrm{C}$ in a $5 \% \mathrm{CO}_{2}$ in air Heracell incubator. Cells were trypsinised using trypsin EDTA (0.05\% Sigma) and collected following incubation for $3 \mathrm{~min}$. The trypsinized cells were removed by adding $4 \mathrm{ml}$ of medium including $4 \%$ fetal calf serum and collected by centrifugation $(800 \mathrm{rpm}$, $10 \mathrm{~min}$, room temperature). The pelleted cells were 


\section{a. P21 normal prostate epithelial cell line}

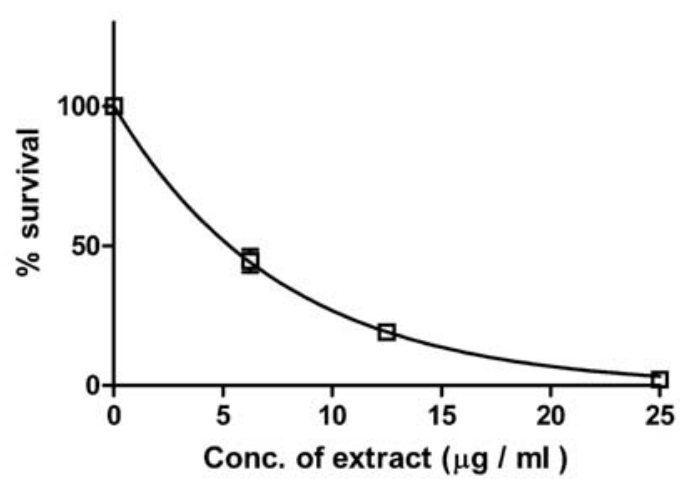

b. P21 prostate tumour cell line 1

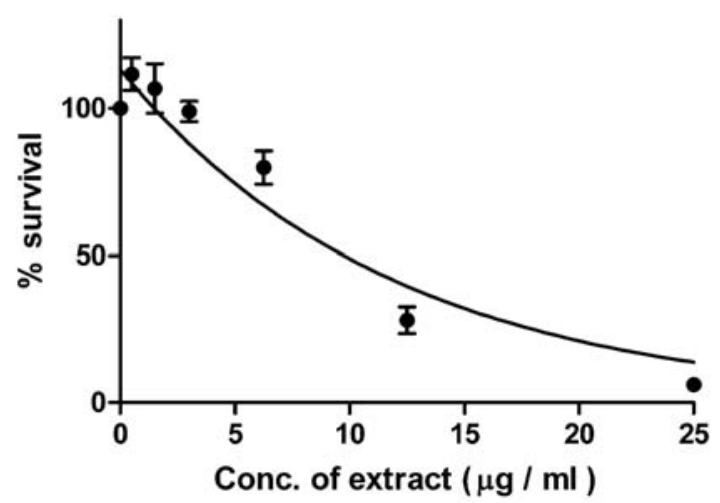

c. P21 prostate tumour cell line 2

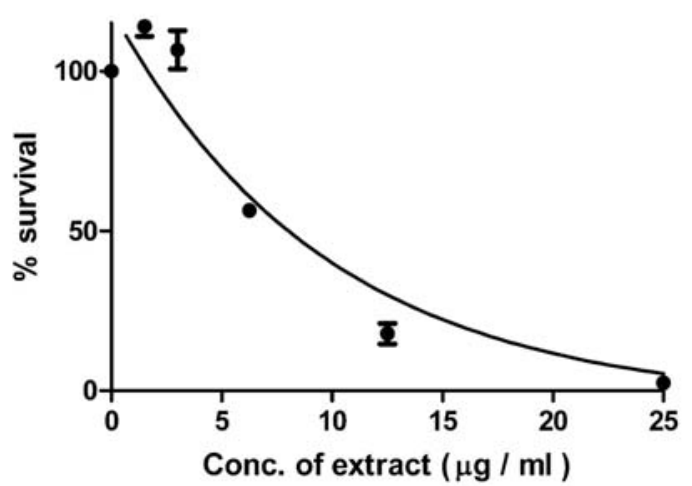

Figure 1. Effects of total strawberry extract on the cell survival of (a) P21 normal prostate epithelial cell line ( $\square$ ) and, (b) the P21 prostate tumour cell line $1(\bullet)$ and (c) the P21 prostate tumour cell line $2(\bullet)$ all cell lines derived from the same patient. Cell survival response is monitored using a cell viability assay. Each value is the mean of at least quadruplicate assays \pm standard error.

re-suspended in $2 \mathrm{ml}$ normal medium and counted to prepare stock solutions of 20,000 cells $/ \mathrm{ml}$.

Cells were pipetted into microtitre plates (NUNC) at 2000 cells/well and incubated at $37^{\circ} \mathrm{C}$ in $5 \% \mathrm{CO}_{2}$ in air for $18 \mathrm{~h}$. Varying concentrations of extract were applied to the cells in $10 \mu 1$ volumes. Blanks of medium and extract were also set up. The plates were incubated for 3 days at $37^{\circ} \mathrm{C} 5 \% \mathrm{CO}_{2}$ in air. The viability of the cells was measured using the Dojindo kit
CCK-8 method after incubation for $3 \mathrm{~h}$ in the absence of light. The plates were read on an ELISA plate reader at a wavelength of $450 \mathrm{~nm}$.

PC-3, LNCaP, and MCF-7 cell lines were grown in RPMI1640 medium supplemented with $10 \%$ FCS, penicillin $(100 \mathrm{mg} / \mathrm{ml})$, streptomycin $(100 \mathrm{U} / \mathrm{ml})$ and $2 \mathrm{mM}$ glutamine (PSG). They were treated in the same manner as described above.

Lymphocytes were obtained by blood donation by anonymous volunteers with full ethical approval (MED 26-06). Histopaque 1077 (10 ml) (Sigma 10771-500 ML) was carefully applied to a $50 \mathrm{~cm}^{3}$ falcon tube and $10 \mathrm{ml}$ blood was layered on top. The sample was centrifuged (2000 rpm, $20 \mathrm{~min}$, room temperature) with the brake off. The interface layer between the Histopaque and the plasma was removed with a sterile fine tipped Pasteur pipette and placed in a sterile $15 \mathrm{~cm}^{3}$ falcon tube. Fresh medium (RPMI-1640 10\% FCS \& PSG) was added and centrifuged (1500 rpm, $5 \mathrm{~min}$, room temperature) to pellet the lymphocytes. These were counted and made up to a stock solution of $10^{6} \mathrm{cells} / \mathrm{ml}$. Cells/well $(100 \mu \mathrm{l})$ were pipetted into 24-well plate and $100 \mu \mathrm{l}$ of PHA (HA15 Biostat stock concentration, $9 \mathrm{mg} / \mathrm{ml}$ ) into the wells. The plate was incubated at $37^{\circ} \mathrm{C}$ in $5 \% \mathrm{CO}_{2}$ in air for $18 \mathrm{~h}$ and strawberry extract was added to the cells as previously described. The plate was incubated for 3 days and cell viability measured as above.

\section{Results}

Effect of strawberry extract on human prostate cell lines. The strawberry polyphenol rich extract had significant cytotoxic effects on the P21 normal prostate epithelial cells, P21 prostate tumour cell line 1 and prostate tumour cell line 2 (Fig. 1). The concentration of whole extract that produced a $50 \%$ reduction in cell survival was $6 \mu \mathrm{g} / \mathrm{ml}$ for the normal prostate cells and 8 and $10 \mu \mathrm{g} / \mathrm{ml}$ for tumour line 1 and 2 , respectively. Thus the normal prostate epithelial cell line P21 was slightly more sensitive to the extract compared to the prostate tumour cell lines (Fig. 1). The established prostatic cancer cell lines LNCaP and PC-3, which are extensively used cell models for aggressive prostate carcinoma (31), were less sensitive than the P21 cell lines (Fig. 2), with concentrations of $\sim 40 \mu \mathrm{g} / \mathrm{ml}$ inducing a $50 \%$ reduction in cell survival.

The effect of the strawberry extract on the morphology of the P21 normal prostate epithelial cell line and the P21 prostate tumour cell line was also observed. At $25 \mu \mathrm{g} / \mathrm{ml}$ of the strawberry extract, very few viable cells were observed for either cell line (Fig. 3) whereas at $5 \mu \mathrm{g} / \mathrm{ml}$, cell survival was $\sim 50 \%$ of control, which is consistent with the data from the cell survival assays (Fig. 1).

Effect of strawberry extract on human breast cell lines. The normal mammary epithelial cell line B42 and the B42 clone 16 tumourigenic partner cell line were both sensitive to the strawberry extract with $6 \mu \mathrm{g} / \mathrm{ml}$ being sufficient to induce a $50 \%$ reduction in cell survival for the normal cells and $4 \mu \mathrm{g} / \mathrm{ml}$ for the tumour cell line (Fig. 4). In this case, the tumourigenic line appeared to be slightly more sensitive than the normal line (Fig. 4). The established breast cancer line (MCF-7) exhibited a similar pattern of response to the 
a. PC3 cell line

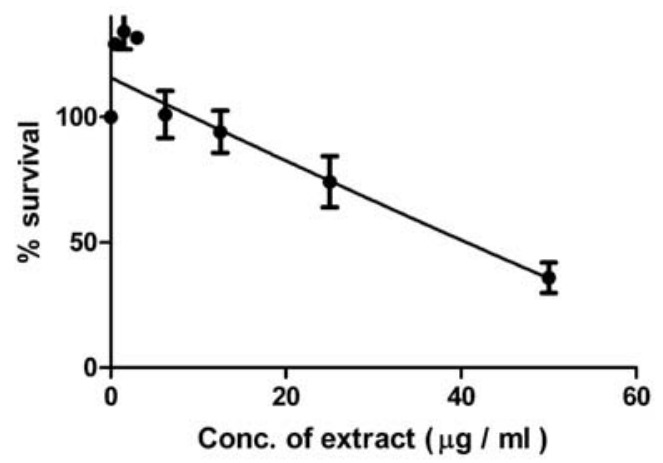

b. LNCaP cell line

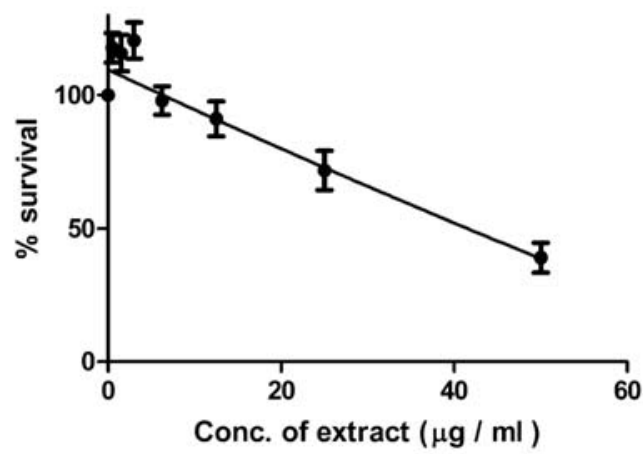

c. LNCaP cell line

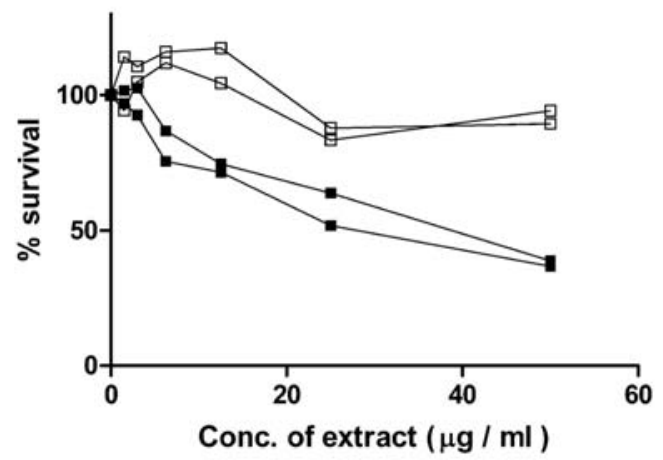

Figure 2. Effects of total strawberry extract on the cell survival of (a) PC3 and (b) LNCaP cell lines. Effects of ( $\square$ ) unbound and ( $\square$ ) bound strawberry fractions on the proliferation of (c) LNCaP cell line. Cell survival response is monitored using a cell viability assay. Each value is the mean of at least quadruplicate assays \pm standard error.

established prostate cell lines. MCF-7 cells were less sensitive to the extract and concentration of $55 \mu \mathrm{g} / \mathrm{ml}$ were required to induce a $50 \%$ reduction in cell survival. Once again, these cells required to be cultured in $10 \%$ fetal calf serum.

Effect of separate strawberry polyphenolic fractions on the human prostate cell lines $P 21$, the $P 21$ prostate tumour cell lines and LNCaP cell line. The composition of the polyphenolrich extract from strawberry was similar to previous studies $(24,32,33)$ and contained anthocyanins, flavonols, hydroxycinnamates, ellagitannins and ellagic acid derivatives
P21S
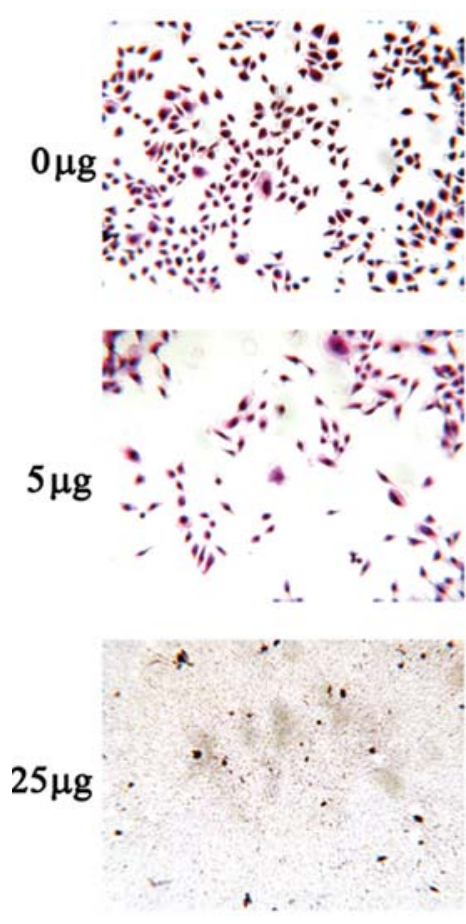

P21 tumour
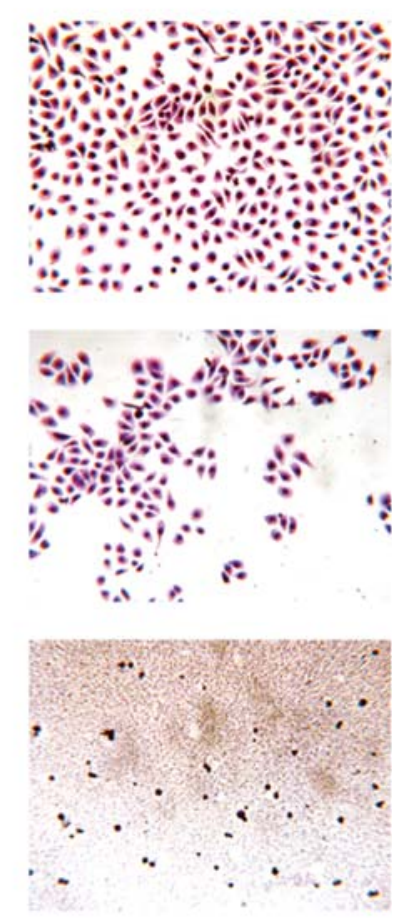

Figure 3. The effects of the total strawberry extract on the morphology of the P21 normal prostate epithelial cell line and the P21 prostate tumour cell line 1 . Cell lines are shown after 3 days exposure to 0,5 and $25 \mu \mathrm{g} / \mathrm{ml}$ total strawberry extract.

and proanthocyanins (Fig. 5; Table I). Two compounds, pelargonidin-3-O-glucoside and pelargonidin-3-O-glucoside malonate, made up the bulk of the anthocyanins. The extract also contained a mixture of quercetin and kaempferol derivatives. The strawberry extract contained a major ellagitannin peak which had a $\mathrm{m} / \mathrm{z}$ value of 935.1 , suggestive of casurictinlike and/or potentillin-like (galloyl diHHDP glucose) structures $(18,34,35)$. Certain peaks could be resolved with $\mathrm{m} / \mathrm{z}$ values consistent with proanthocyanidins previously identified in strawberry $(24,32,33)$ but other proanthocyanins were poorly resolved from other components in the region between 25-35 $\mathrm{min}$.

After chromatography on Sephadex LH20, the components in the original sample (Fig. 5a) were split between the unbound (Fig. 5b) and bound samples (Fig. 5c). Most of the components, in particular the anthocyanins, hydroxycinnamates and the flavonols, remained in the unbound sample leaving a bound sample mainly enriched in proanthocyanidins and ellagitannins. For example, the bound fraction contained $\sim 0.2 \%$ of the pelargonidin glucoside peak of total strawberry sample.

As well as the proanthocyanindin peaks discerned in the total strawberry sample, the bound fraction was enriched in the poorly resolved proanthocyanidin peaks in the region around RT 25-25. In this region, peaks with $m / z$ values characteristic of procyanidin dimers, trimers, tetramers and pentamers (577.1, 865.1, 1153.1, 1441.1 and 1729.0 (36) could be identified by searching the MS data at specific masses (results not shown). In addition, $\mathrm{m} / \mathrm{z}$ signals characteristic of propelargonidin proanthocyanidin dimers to pentamers (i.e. proanthocyanidins containing at least one (epi)afzelechin unit and (epi)catechin 


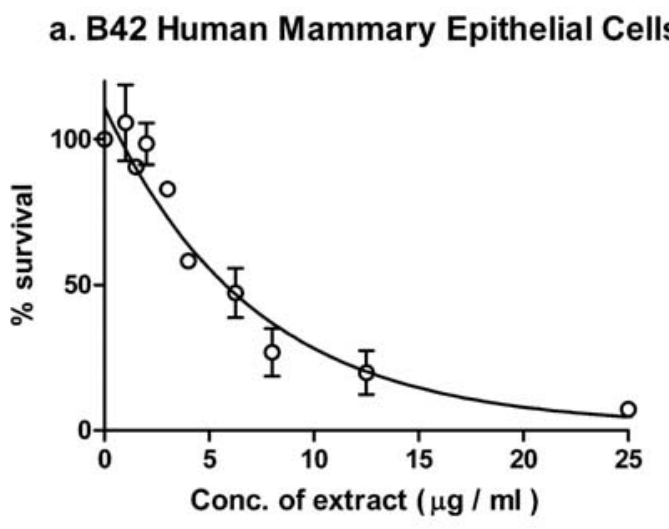

\section{b. B42 clone 16 tumour cell line}

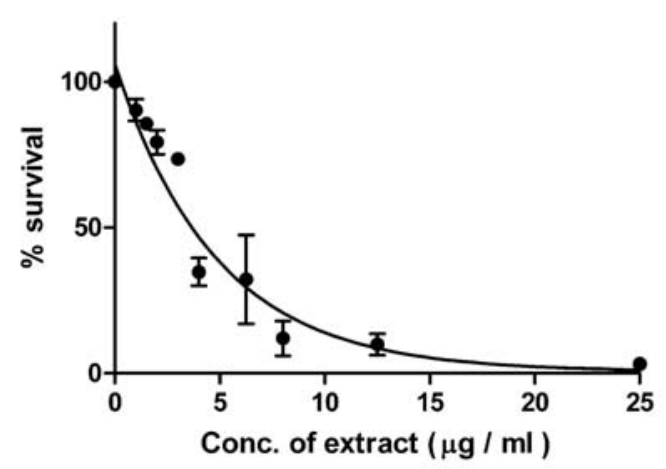

\section{c. MCF7 breast ca line}

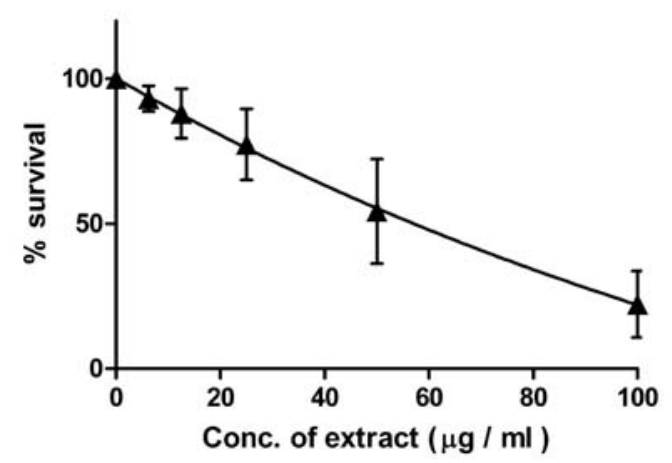

Figure 4. Effects of total strawberry extract on the cell survival of (a) normal B42 human mammary epithelial cells (०), (b) B42 clone 16 mammary tumour cell line (•) and (c) MCF-7 cell line (₫). Cell survival response is monitored using a cell viability assay. Each value is the mean of at least quadruplicate assays \pm standard error.

units) at $m / z$ 561.0, 833.0, 849.1, 1121.1, 1137.0, 1409.0 and 1425.0 could also be identified (results not shown). The enrichment of proanthocyandins in strawberry LH20 bound fractions has been reported previously but the proanthocyanidin pattern obtained in this case was different than previous studies (18) as the LH20 fractionation involved an extensive wash with $50 \%$ ethanol which preferentially selected certain smaller proanthocyanidins. This was particularly noticeable in the reduction of the procyanidin dimer peaks 5 and 6 (results not shown).

The tannin-rich bound fraction was considerably more toxic to the human prostate cells than the anthocyanin-rich

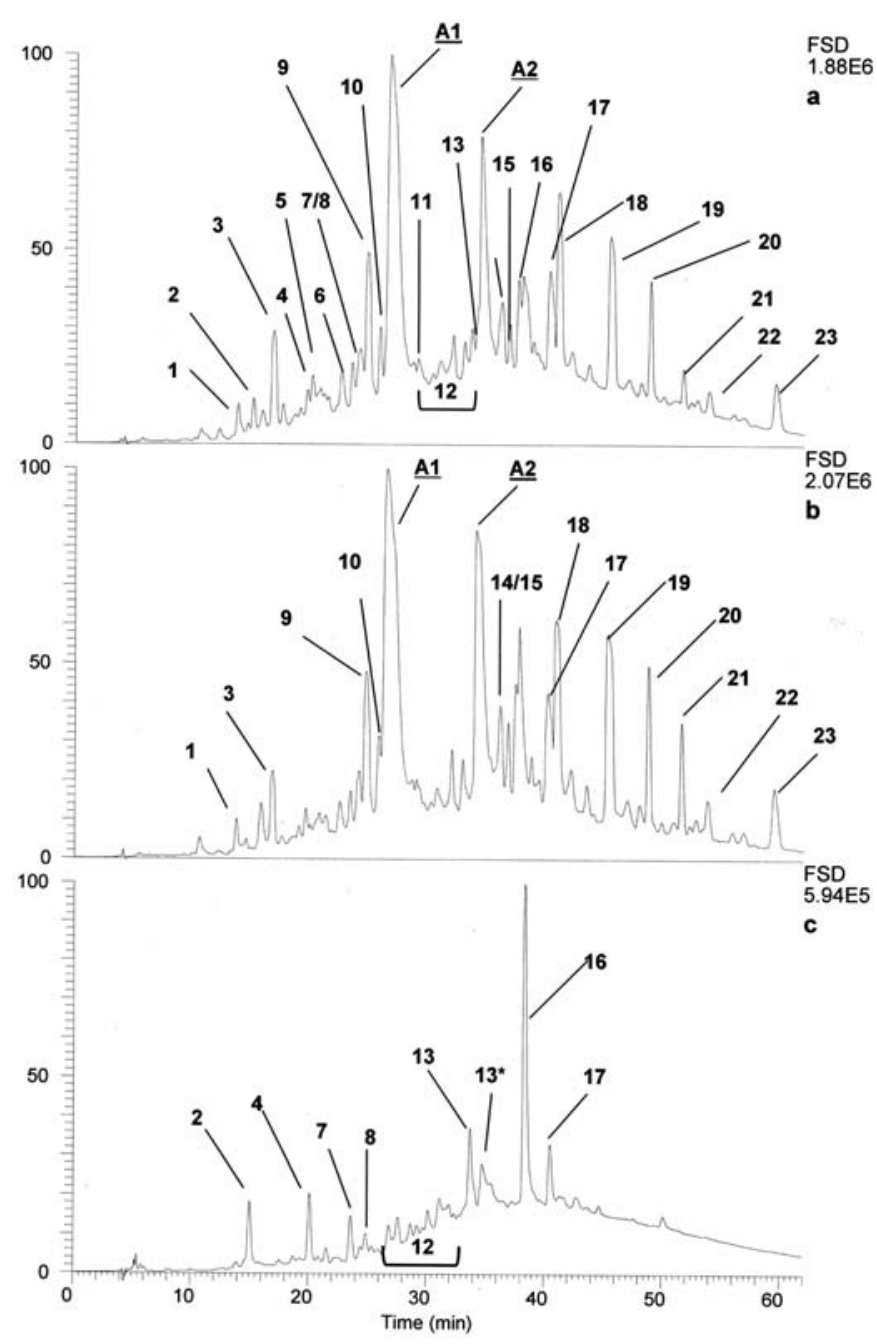

Figure 5. LC-MS of total, unbound and bound strawberry fractions. (a) The trace at $280 \mathrm{~nm}$ of the total strawberry extract, (b) the trace at $280 \mathrm{~nm}$ of the unbound fraction following Sephadex LH20 chromatography, (c) trace at $280 \mathrm{~nm}$ of the bound fraction following Sephadex LH20 chromatography. Individual peak numbers refer to Table I. The FSD figure is the full scale deflection of the PDA detector. Peak $13^{*}$ appears to be identical to peak 13 and may be an isomeric form.

unbound fraction with $\sim 6 \mu \mathrm{g} / \mathrm{ml}$ required for a $50 \%$ reduction in cell survival (Fig. 6). This value was similar to the total strawberry extract. The bound fraction was equally toxic to the P21 normal and tumour cell lines. The unbound fraction was much less cytotoxic in both the P21 normal and tumour cell lines with $90-100 \%$ cell survival at $25 \mu \mathrm{g} / \mathrm{ml}$. The established LNCaP tumour cell line was also more sensitive to the tannin-rich bound fraction (Fig. 2).

Effects of the total strawberry extract, unbound and bound extracts on PHA stimulated growth of human lymphocytes. Increasing concentrations of the strawberry extract caused a dose responsive cytotoxicity on human lymphocytes (Fig. 7). The effect was consistent between lymphocytes gathered from three different volunteers, although the magnitude of the response was volunteer-dependent. The PHA-stimulated lymphocytes were considerably less sensitive to the total strawberry extract than the prostate P21 and mammary B42 cell lines and required a higher concentration $(35-45 \mu \mathrm{g} / \mathrm{ml})$ to reduce survival by $50 \%$ (Fig. 6). However, the lymphocytes 
Table I. Polyphenolic composition of strawberry fractions.

\begin{tabular}{|c|c|c|c|c|c|}
\hline Peak & RT & Amax PDA & $M / Z(\mathrm{M}-\mathrm{H})$ & $\mathrm{MS}^{2}$ & Putative ID \\
\hline 1 & 13.80 & 275 & - & - & UK \\
\hline 2 & 15.11 & $260-290$ & 783.2, $481.2,301.3,275.3$ & $481.1, \mathbf{3 0 1 . 3}, 275.2$ & Pedunculagin-like ellagitannin \\
\hline 3 & 16.83 & $270-290$ & - & - & UK \\
\hline 4 & 20.14 & $260-290$ & $\mathbf{7 8 3 . 2}, 481.2,301.3,275.3$ & $481.1, \mathbf{3 0 1 . 3}, 275.2$ & Pedunculagin-like ellagitannin \\
\hline 5 & 21.12 & 275 & $\mathbf{5 7 7 . 2}, 425.2,407.3,289.2$ & $451.1, \mathbf{4 2 5 . 1}, 407.2,289.2$ & PAC dimer \\
\hline 6 & 22.51 & 275 & $\mathbf{5 7 7 . 2}, 425.2,407.3,289.2$ & $451.1, \mathbf{4 2 5 . 1}, 407.2,289.2$ & PAC dimer \\
\hline 7 & 23.50 & 275 & $\mathbf{8 6 5 . 2}, 577.2,407.3,289.2$ & Multiple & PAC trimer \\
\hline 8 & 24.18 & 275 & $\mathbf{5 7 9 . 2}, 289.2$ & 289.2 & PAC dimer \\
\hline 9 & 24.83 & 320 & 325.1 & $187.1,163.0, \mathbf{1 4 5 . 2}$ & Hydroxy-cinnamate derivative \\
\hline 10 & 25.87 & 315 & 325.1 & $187.1,163.0, \mathbf{1 4 5 . 2}$ & Hydroxy-cinnamate derivative \\
\hline A1 & 26.75 & 495,280 & $\mathbf{+ 4 3 3 . 0 , 2 7 1 . 3}$ & 271.3 & Pelargonidin glucoside \\
\hline 11 & 29.07 & 280 & $\mathbf{8 6 5 . 2}, 577.2,289.2$ & 289.2 & PAC trimer \\
\hline 12 & $30-33$ & 285 & Multiple & - & PACs \\
\hline 13 & 33.70 & 280 & $\mathbf{9 3 5 . 2}, 301.2$ & 633.2, $452.2,301.3$ & Potentillin-like ellagitannin \\
\hline $\mathrm{A} 2$ & 34.45 & 500,285 & $\mathbf{+ 5 1 9 . 0 ,} 271.2$ & 271.2 & Pelargonidin malonyl glucoside \\
\hline 14 & 36.22 & 280 & 751.0 & - & UK \\
\hline 15 & 36.89 & 355 & +611.0, (633.1) 303.3 & 303.3 & Quercetin rutinoside \\
\hline 16 & 38.32 & 285 & $\begin{array}{l}\text { 1869.0, 1567.1, 935.2, } \\
783.2,301.2\end{array}$ & $\begin{array}{l}\text { 15687.0, 1265.2, 1095.1, } \\
935.1,633.2\end{array}$ & Sanguiin H10-like ellagitannin \\
\hline 17 & 40.30 & 370 & 301.3 & $301.3,275.1$ & Ellagic acid \\
\hline 18 & 41.06 & 370 & 477.2, 301.3 & 301.3 & Ellagic acid glucuronide \\
\hline $19 \mathrm{~A}$ & 45.45 & 340 & $\mathbf{+ 4 4 9 . 2 , 2 8 7 . 3}$ & 287.3 & Kaempferol glucoside \\
\hline 19B & 45.45 & 340 & $\mathbf{+ 4 6 3 . 1 , 2 8 7 . 3}$ & 287.3 & Kaempferol glucuronide \\
\hline 20 & 48.88 & 345 & $\mathbf{+ 5 3 5 . 1 , ( 5 5 7 . 1 ) , 2 8 7 . 3}$ & 287.2 & Kaempferol malonyl glucoside \\
\hline 21 & 51.69 & 345 & $\mathbf{+ 5 3 5 . 1 , ( 5 5 7 . 1 ) , 2 8 7 . 3}$ & 287.2 & Kaempferol malonyl glucoside \\
\hline 22 & 53.88 & 275 & - & - & UK \\
\hline 23 & 59.57 & 275 & - & - & UK \\
\hline
\end{tabular}

All peak numbers refer to Fig. 4. In bold are the main $M / Z$ or $\mathrm{MS}^{2}$ signals; +, signal in positive mode and numbers in parentheses are characteristic sodium adducts of flavonols. UK, unknown; PAC, proanthocyanidin.

are cultured in $10 \%$ fetal calf serum, which may influence the availability of polyphenols. It is notable and relevant that the lymphocytes were as sensitive to the strawberry extract as the established prostate cancer lines (LNCap and PC-3, Fig. 2) and were more sensitive than the established breast cancer cell line (MCF-7, Fig. 4). The bound tannin-rich fraction was more effective than the total extract with $20-35 \mu \mathrm{g} / \mathrm{ml}$ giving a $50 \%$ reduction in cell survival (Fig. 7). The anthocyanin-rich unbound extract caused slight inhibition of growth at low concentrations but cell survival never decreased below $~ 70 \%$ regardless of the concentration used. Low concentrations of the total strawberry extract enhanced growth of the P21d clone, the LNCaP and PC-3 cell lines (Fig. 2), B42 normal line (Fig. 4) and the lymphocytes (Fig. 7).

\section{Discussion}

It is clear from epidemiological studies (1-4) and the limited in vivo studies (e.g. 15) that polyphenolic compounds can have an effect on the induction of cancer and thus may have an important role in preventing cancer. This needs to be distinguished from studies where the direct effects of these compounds on cultured tumour cells has been investigated.
The polyphenol-rich strawberry extract had significant cytotoxic effects on normal and tumourigenic prostate and breast cell lines but there was little evidence for differential cytotoxicity at the concentrations used. As the serum bioavailability of many berry polyphenols (37) is much lower than the levels required for inhibition of cell proliferation in this study, it is very unlikely that breast or prostate cancer cells would ever be exposed to these levels in vivo through normal diets. However, it is possible that differential cytotoxicity could be elicited at lower concentrations and this may be especially relevant between the B42 normal breast cells and the B42 clone 16 tumour cells (see Fig. 4). Future work will focus on the effects of long-term treatments at lower, more physiologically relevant concentrations.

Research into the effect of polyphenols on prostate and breast cell lines so far has been limited. Grape seed extract has been tested on human prostate cancer cell lines DU145 and LNCaP and human breast cancer cell lines MCF-7 and MDA-MB468 in vitro $(11,38,39)$. The extracts had irreversible growth inhibitory effects on all the cell lines and apparently caused this effect via mitogenic signalling and induction of cell cycle G1 arrest. A multitude of berry extracts were tested on LNCaP and MCF-7 lines and were found to all inhibit cell 


\section{a. P21 normal prostate epithelial cell line}

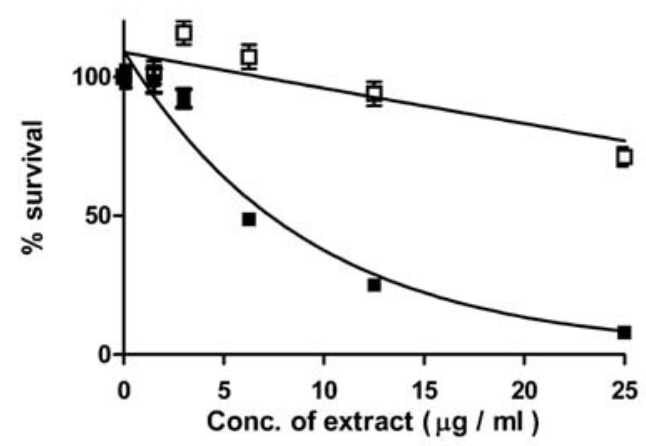

b. P21 prostate tumour cell line 1

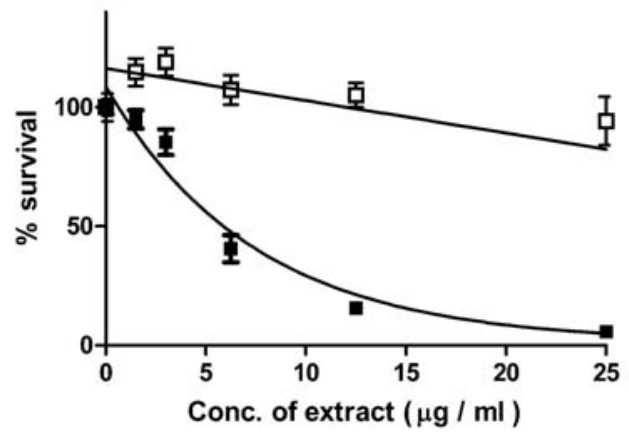

c. P21 prostate tumour cell line 2

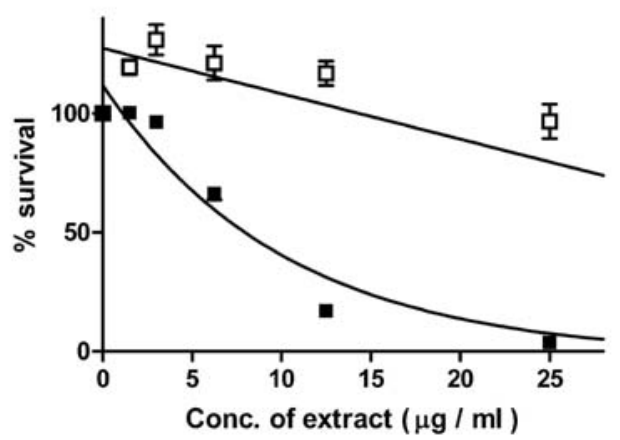

Figure 6. Effects of ( $\square$ ) unbound and ( $\square$ ) bound strawberry fractions on the proliferation of (a) the P21 normal prostate epithelial cell line, (b) the P21 prostate tumour cell line 1 and (c) the P21 prostate tumour cell line 2; all cell lines derived from the same patient. Cell survival response is monitored using a cell viability assay. Each value is the mean of at least quadruplicate assays \pm standard error.

proliferation (24). Further research looked at the effect of the polyphenolic compounds on human prostate cancer cells in an environment mimicking the body. Pomegranate juice extracts were reported to inhibit the invasion of the human prostate cancer cell line PC-3 in vitro across a Matrigel ${ }^{\mathrm{TM}}$ membrane but the mechanism is unknown (40).

As noted in the introduction, there have been many studies suggesting effectiveness of berry extracts or polyphenol components against cancer cells and these have often been followed by studies unravelling the possible mechanisms for selective cytotoxicity such as influencing signal transduction pathways (41) and disruption of calcium homeostasis (22) or cell cycle control (41). However, fewer studies have incorpo-

\section{a. subject 1}

\section{Human PHA stimulated lymphocytes}

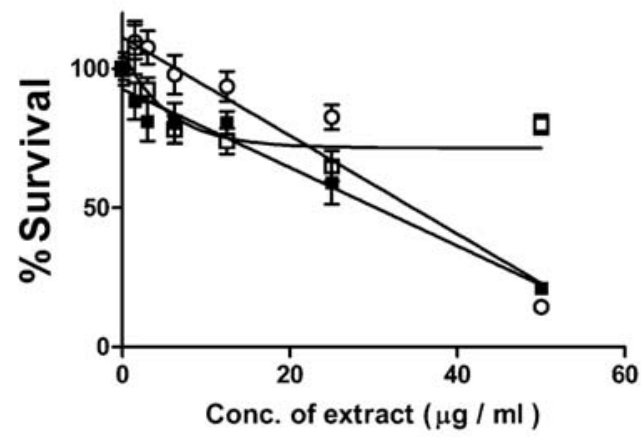

b. subject 2

\section{Human PHA stimulated lymphocytes}

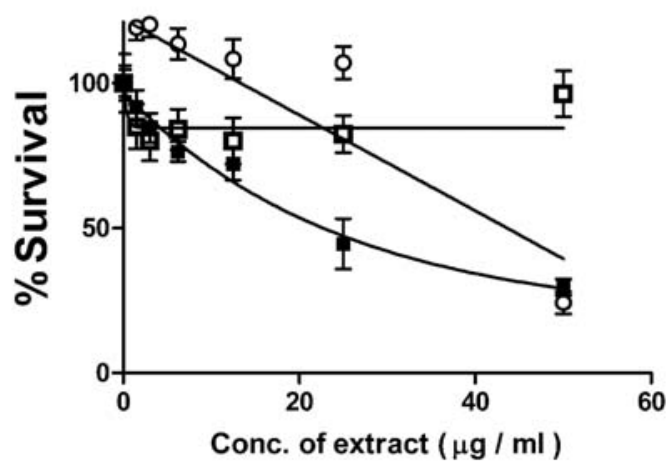

c. subject 4 and 5

Human PHA stimulated lymphocytes

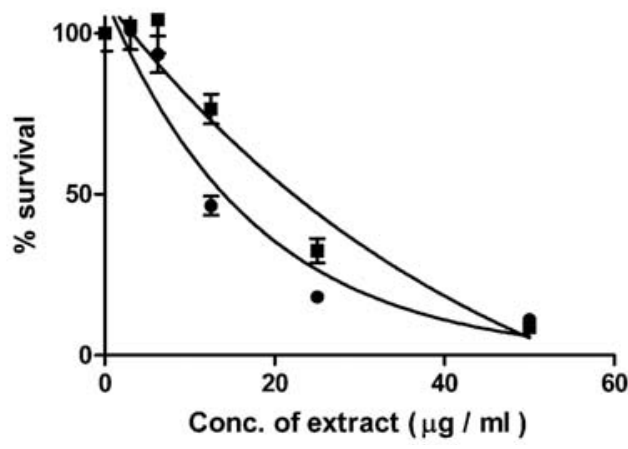

Figure 7. Effects of $(\odot)$ total, $(\square)$ unbound and (ロ) bound strawberry fractions on the cell survival of peripheral blood lymphocytes stimulated with PHA. (a) subject 1, (b) subject 2 and (c) subject 4 and 5. Cell survival response is monitored using a cell viability assay. Each value is the mean of at least quadruplicate assays \pm standard error.

rated controls using 'normal' cells and often these cells are non-identical or non-equivalent to the physiological origin of the cancer cells. For example, it has been reported that polyphenolic compounds have a cancer cell-specific effect using a rapidly proliferating cell line such as HeLa for the tumour model and a slower growing premalignant cell line such as HaCat keratinocytes as a normal comparator (42). In such situations, it could be expected that the extract would affect 
the more rapidly proliferating cells more potently. Also, subfractions of grape seed extract enriched in various proanthocyanidins were found to be cytotoxic against cultured L1210 mouse leukaemia cells and HepG2 liver cancer cells but ineffective against normal PK15 pig kidney cells (43). However, the validity of this comparison may be poor as the liver and leukaemic cells are physiologically and metabolically very different from the pig kidney cells. Other researchers have reported selective cytotoxicity of polyphenols or polyphenol-rich extracts using other 'normal' cells that are not physiologically-related to the cancer cells under study. For example, ellagic acid was found to be selectively cytotoxic to a range of cultured cancer cell lines (colon, breast and prostatic) compared to normal human embryonic lung fibroblast HEL 299 cells (44). Crude gallotannins have been shown to be cytotoxic against human HCT 116, HT-29 and DLD-1 colon cancer cells but much less cytotoxic against normal human intestinal FHs74Int epithelial cells (23).

The use of PHA-stimulated lymphocytes as normal cells is common (45) but may not be relevant as a normal comparator for certain cancer lines. The anthocyanin, cyanidin rutinoside, was found to be selectively cytotoxic against the HL-60 leukaemic cancer line (46) compared to PHA-stimulated human lymphocytes. On the other hand, the comparison of selective cytotoxicity of a pomegranate extract, enriched in ellagitannins and anthocyanins, against human lung carcinoma A549 cells compared to normal bronchial epithelial cells (47) which share a common physiological background seems more relevant.

In comparative studies against directly equivalent normal cells, selective cytotoxicity of polyphenol components against cancer cells is not always reported. Liesveld et al (48) found that quercetin showed no differential cytotoxic effects against normal CD34+ haematopoietic progenitor cells or acute myeloid leukemic cells (20). Sub-fractions of black raspberry extracts (20), probably enriched in anthocyanins, were selectively cytotoxic against pre-malignant and malignant oral cell lines but not against normal oral cell lines. However, another more hydrophobic sub-fraction, probably enriched in ellagitannins, was equally cytotoxic to normal, premalignant and malignant cells. In addition, ellagic acid was more cytotoxic against normal than the pre-malignant and malignant oral cell lines (20). Red wine polyphenols were equally cytotoxic against normal human mammary epithelial cells and the tumourigenic breast epithelial cell line MCF-7 (49) although sub-fractions of unknown composition showed some selectivity towards the tumourigenic cell line $(22,49)$. On the other hand, polyphenol-rich cocoa extracts were differentially cytotoxic against prostate cancer cell lines DU145 and 22Rv1 compared to a normal prostate epithelial cell line (21). Human breast cancer and normal cell lines treated with red wine polyphenols (22) and colon cancer and normal gastric mucosal cells treated with gallotannin and proanthocyanidin extracts $(11,23)$ both exhibited differential cytotoxicity.

The strawberry bound fraction, which was enriched in ellagitannins and proanthocyanidins, was most cytotoxic against normal and tumourigenic clones and lymphocytes. Recent studies have shown that ellagitannin-rich fractions from raspberry were effective anti-proliferative agents against
HeLa cells (25) and proanthocyanidin-enriched fractions were the most effective antiproliferative components from lingonberry against $\mathrm{CaCo}-2$ cells (18). Therefore, there could be considerable synergy between these two tannin components in strawberry. In addition, others have reported on the effectiveness of proanthocyanidins from grape and pine (50) and from apple (51) and have noted a trend that larger proanthocyanidins are more cytotoxic. At low concentrations of the extracts, cell survival was actually increased in the prostate, breast and lymphocyte cell lines (Figs. 1, 2, 4, 6 and 7). This positive effect has also been reported for grape seed proanthocyanidins on normal human gastric mucosal cells and J774A murine macrophage cells (11) and for anthocyaninenriched fractions on HeLa cells (25).

Polyphenolic compounds from fruits such as green tea (52), strawberries (19), raspberries (53) blackberries (24) and grapes (11) have anti-carcinogenic effects and also interfere with the proliferation, induce G1 cell cycle arrest and apoptosis in tumour cells. This suggests that the polyphenolic compounds are affecting the cells by preventing them from completing the cell cycle and forcing them into apoptosis $(41,54)$.

Other workers have shown that strawberry polyphenolic compounds can cause up-regulation of the expression of $\mathrm{p} 21^{\mathrm{WAF} 1}$, a cyclin kinase inhibitor, and have speculated that the inhibition of cell proliferation is via the $\mathrm{p} 21^{\mathrm{WAF} 1}$ pathway (41). The human prostate cell line DU145 was shown to undergo cell cycle G1 arrest after treatment with grape seed polyphenolic extract (38) with corresponding 90\% decrease in levels of cdk4. In another study, treatment of prostate cancer cells with strawberry polyphenols down-regulated cdk4 but also down-regulated expression of cdk6, cyclin D1 and cyclin D3 (54). This suggests that the polyphenolic compounds are causing an up-regulation of $\mathrm{p} 21^{\mathrm{WAF} 1}$ that, in turn, inhibits binding of cdk4 and cdk6 to their respective cyclins D1 and D3 and prevents the cells from progressing from G1 into $S$ phase and instead undergoing apoptosis. However, the levels of p $21^{\mathrm{WAF}}$ have to be high enough to inhibit expression of cdk4 and cdk6 as a low base line of expression would enable the cdk 4 and cdk6 to bind their respective cyclins and allow cells to progress through the cell cycle. Hence p $21^{\mathrm{WAF} 1}$ has a negative and positive effect on G1 progression through the cell cycle (55). While these results are interesting, what is more important is whether the plant extracts have a differential effect on normal versus tumour cells.

However, there have been few studies on the cell cycle responses of normal cells to these compounds and these suggested anti-cancer mechanisms may not be specific and represent a normal mechanism of cell death.

Interestingly, the well established malignant cell lines derived from prostate and breast cancers are more resistant to the polyphenol compounds compared to the prostate and breast cell lines derived in this study. The difference in sensitivity could be due to the fact that the established cell lines require to be cultured in $10 \%$ fetal calf serum whereas the other lines are grown in serum-free conditions which will influence the availability of certain polyphenol components (25). Thus, higher concentrations of polyphenols are required to elicit the same effect.

Further work needs to be carried out to investigate the upregulation and down-regulation of cell cycle genes to see if the 
strawberry polyphenolic extract is causing apoptosis via the p21 pathway and why the established cell lines LNCaP, PC-3 and $\mathrm{MCF}-7$ are more resistant. We speculate that the polyphenols could be manipulated via a drug delivery system so that only the cancer cells are affected.

In conclusion, our studies strongly suggest that polyphenolic compounds from fruit are not cancer cell-specific and that the mechanisms behind polyphenol cytotoxicty, be it cell cycle signalling or other pathways, require more thorough investigation.

\section{Acknowledgements}

We would like to acknowledge the Wolfson Intercalated Awards Programme for funding Mimi Hou and the University of St. Andrews for a PhD scholarship to support Jennifer Weaver.

\section{References}

1. Anon: Joint WHO/FAO Expert Consultation on Diet, Nutrition and the Prevention of Chronic Diseases. WHO technical report series, Geneva, 2002.

2. Steinmetz KA and Potter JD: Vegetables, fruit and cancer prevention: A review. J Am Diet Assoc 96: 1027-1039, 1996.

3. Simopoulos AP: The Mediterranean diets: What is so special about the diet of Greece? The scientific evidence. J Nutr 131: S3065-S3073, 2001.

4. Norman HA, Go VL and Butrum RR: Review of the international research conference on food, nutrition, and cancer 2004. J Nutr 134: S3391-S3393, 2004.

5. Duthie SJ: Berry phytochemicals, genomic stability and cancer. Mol Nutr Food Res 51: 665-674, 2007.

6. Halliwell B: Free radicals, proteins and DNA: oxidative damage versus redox regulation. Biochem Soc Trans 24: 1023-1027, 1996.

7. Freese R: Markers of oxidative DNA damage in human interventions with fruit and berries. Nutr Cancer 54: 143-147, 2006.

8. Evan GI and Vousden KH: Proliferation, cell cycle and apoptosis in cancer. Nature 411: 342-348, 2001

9. Zhang Y, Seeram NP, Lee R, Feng L and Heber D: Isolation and identification of strawberry phenolics with antioxidant and human cancer cell antiproliferative properties. J Agric Food Chem 56: 670-675, 2008

10. Zhao C, Giusti MM, Malik M, Moyer, MP and Magnuson BA: Effects of commercial anthocyanin-rich extracts on colonic cancer and nontumourigenic colonic cell growth. J Agric Food Chem 52: 6122-6128, 2004

11. Ye X, Krohn RL, Liu W, et al: The cytotoxic effects of a novel IH636 grape seed proanthocyanidin extract on cultured human cancer cells. Mol Cell Biochem 196: 99-108, 1999.

12. Misikangas M, Paraji AM, Paivarinta E, et al: Three nordic berries inhibit intestinal tumourigenesis in multiple intestinal neoplasia/+ mice by modulating $\beta$-catenin signalling in the mucosa. J Nutr 137: 2285-2290, 2007

13. Bobe G, Wang B, Seeram NP, Nair MG and Bourquin LD: Dietary anthocyanin-rich tart cherry extract inhibits intestinal tumorigenesis in APC(Min) mice fed suboptimal levels of sulindac. J Agric Food Chem 54: 9322-9328, 2006.

14. Carlton PS, Kresty LA, Siglin JC, Morse MA, Lu J, Morgan C and Stoner GD: Inhibition of N-nitrosomethylbenzylamineinduced tumorigenesis in the rat oesophagus by dietary freezedried strawberries. Carcinogenesis 22: 441-446, 2001

15. Stoner GD, Wand LS, Zikri N, et al: Cancer prevention with freeze-dried berries and berry components. Semin Cancer Biol 17: 403-410, 2007

16. Katsube N, Iwashita K, Tsushida T, Yamaki K and Kobori M: Induction of apoptosis in cancer cells by bilberry (Vaccinium myrtillus) and the anthocyanins. J Agric Food Chem 51: 68-75, 2003.

17. Yi W, Akoh CC, Fischer J and Krewer G: Absorption of anthocyanins from blueberry extracts by Caco- 2 human intestinal cell monolayers. J Agric Food Chem 54: 5651-5658, 2006.
18. McDougall GJ, Ross HA, Ikeji M and Stewart D: Berry extracts exert different antiproliferative effects against cervical and colon cancer cells grown in vitro. J Agric Food Chem 56: 3016-3023, 2008.

19. Ramos S, Alia M, Bravo L and Goya L: Comparative effects of food-derived polyphenols on the viability and apoptosis of a human hepatoma cell line (HepG2). J Agric Food Chem 53: 1271-1280, 2005.

20. Han C, Ding H, Casto B, Stoner GD and D'Ambrosio SM: Inhibition of the growth of premalignant and malignant human oral cell lines by extracts and components of black raspberries. Nutr Cancer 51: 207-217, 2005.

21. Jourdain C, Tenca G, Deguercy A, Troplin P and Poelman D: In-vitro effects of polyphenols from cocoa and B-sitosterol on the growth of human prostate cancer and normal cells. Eur J Cancer Prev 15: 353-361, 2006.

22. Hakimuddin F, Paliyath G and Meckling K: Treatment of Mcf-7 breast Cancer cells with a red grape wine polyphenol fraction results in disruption of calcium homeostasis and cell cycle arrest causing selective cytotoxicity. J Agric Food Chem 54: 7912-7923, 2006.

23. Al-Ayyoubi S and Gali-Muhtasib H: Differential apoptosis by gallotannin in human colon cancer cells with distinct p53 status. Mol Carcinog 46: 176-186, 2007.

24. Seeram NP, Adams LS, Zhang Y, Lee R, Sand D, Scheuller HS and Heber D: Blackberry, black raspberry, blueberry, cranberry, red raspberry, and strawberry extracts inhibit growth and stimulate apoptosis of human cancer cells in vitro. J Agric Food Chem 54: 9329-9339, 2006

25. Ross H, McDougall GJ and Stewart D: Antiproliferative activity is predominantly associated with ellagitannins in raspberry extracts. Phytochemistry 68: 218-228, 2007.

26. Zhang Y, Seeram NP, Lee R, Feng L and Heber D: Isolation and identification of strawberry phenolics with antioxidant and human cancer cell antiproliferative properties. J Agric Food Chem 56: 670-675, 2008.

27. Singleton VL and Rossi JA Jr: Colorimetry of total phenolics with phosphomolybdic-phosphotungstic acid reagents. Am J Enol Vitic 16: 144-158, 1965.

28. Ramirez RD, Sheridan S, Girard L, et al: Immortalization of human bronchial epithelial cells in the absence of viral oncoproteins. Cancer Res 64: 9027-9034, 2004.

29. Zitzelsberger H, Hieber L, Richter H, Unger K, Briscoe CV, Peddie C and Riches A: Gene amplification of atypical PKCbinding PARD3 in radiation-transformed neoplastic retinal pigment epithelial cell lines. Genes Chromosomes Cancer 40: $55-59,2004$.

30. Romanov SR, Kozaklewicz BK, Holst CR, Stampfer MR, Haupt LM and Tlsty TD: Normal human mammary epithelial cells spontaneously escape senescence and acquire genomic changes. Nature 409: 633-637, 2001.

31. Kampa M, Hatzoglou A, Notas G, et al: Wine antioxidant polyphenols inhibit the proliferation of human prostate cancer cell lines. Nutr Cancer 37: 223-233, 2000.

32. Macheix JJ, Fleuriet A and Billot J: Fruit Phenolics. CRC Press, Boca Raton, FL, 1990.

33. Aaby K, Skrede G, and Wrolstad RE: Phenolic composition and antioxidant activities in flesh and achenes of strawberries (Fragaria ananassa). J Agric Food Chem 53: 4032-4040, 2005.

34. Hukkanen AT, Kokko HI, Buchala AJ, McDougall GJ, Stewart D, Karenlampi SO and Karjalainen RO: Benzothiadiazole induces the accumulation of phenolics and improves resistance to powdery mildew in strawberries. J Agric Food Chem 55: 1862-1870, 2007.

35. Hager TJ, Howard LR, Liyanage R, Lay JO and Prior RL: Ellagitannin composition of blackberry as determined by HPLCESI-MS and MALDI-TOF-MS. J Agric Food Chem 56: 661-669, 2008.

36. Gu L, Kelm MA, Hammerstone JF, Beecher G, Holden J, Haytowitz D and Prior RL: Screening of foods containing proanthocyanidins and their structural characterization using LC-MS/MS and thiolytic degradation. J Agric Food Chem 51: 7513-7521, 2003.

37. Williamson G, and Manach C: Bioavailability and bioefficacy of polyphenols in humans. II. Review of 93 intervention studies. Am J Clin Nutr 81: S243-S255, 2005

38. Agarwal C, Sharma Y and Agarwal R: Anticarcinogenic effect of a polyphenolic fraction isolated from grape seeds in human prostate carcinoma DU145 cells: modulation of mitogenic signaling and cell-cycle regulators and induction of G1 arrest and apoptosis. Mol Carcinog 28: 129-138, 2000. 
39. Agarwal C, Sharma Y, Zhao J and Agarwal RA: Polyphenolic fraction from grape seeds causes irreversible growth inhibition of breast carcinoma MDA-MB468 cells by inhibiting mitogenactivated protein kinases activation and inducing G1 arrest and differentiation. Clin Cancer Res 6: 2921-2930, 2000.

40. Lansky EP, Harrison G, Froom P and Jiang WG: Pomegranate (Punica granatum) pure chemicals show possible synergistic inhibition of human PC-3 prostate cancer cell invasion across Matrigel $^{\mathrm{TM}}$. Invest New Drugs 23: 121-122, 2005.

41. Wu QK, Koponen JM, Mykkanen HM and Torronen AR: Berry phenolic extracts modulate the expression of p21(WAF1) an Bax but not Bcl-2 in HT-29 colon cancer cells. J Agric Food Chem 55: 1156-1163, 2007.

42. Aparicio-Fernandez X, Garcia-Gasca T, Yousef GG, Lila MA, Gonzalez de Mejia E and Loarca-Pina G: Chemopreventive activity of polyphenolics from Black Jamapa Bean (Phaseolus vulgaris L.) on HeLa and HaCaT cells. J Agric Food Chem 54: 2116-2122, 2006.

43. Jo JY, de Mejia EG and Lila MA: Cytotoxicity of bioactive polymeric fractions from grape cell culture on human hepatocellular carcinoma, murine leukemia and non-cancerous PK15 kidney cells. Food Chem Toxicol 44: 1758-1767, 2006.

44. Losso JN, Bansode RR, Trappey A, Bawadi HA and Truax R: In vitro anti-proliferative activities of ellagic acid. J Nutr Biochem 15: 672-678, 2004.

45. Hernandez P, Rodriguez PC, Delgado R and Walczak H: Protective effect of Mangifera indica L. polyphenols on human T lymphocytes against activation-induced cell death. Pharmacol Res 55: 167-173, 2007.

46. Feng R, Ni HM, Wang SY, Tourkova IL, Shurin MR, Harada H and Yin XM: Cyanidin-3-rutinoside, a natural polyphenol antioxidant, selectively kills leukemic cells by induction of oxidative stress. J Biol Chem 282: 13468-13476, 2007.
47. Khan N, Hadi N, Afaq F, Syed DN, Kweon MH and Mukhtar H: Pomegranate fruit extract inhibits prosurvival pathways in human A549 lung carcinoma cells and tumor growth in athymic nude mice. Carcinogenesis 28: 163-173, 2007.

48. Liesveld JL, Abboud CN, Lu C, et al: Flavonoid effects on normal and leukemic cells. Leuk Res 27: 517-527, 2003.

49. Hakimuddin F, Paliyath G and Meckling K: Selective cytotoxicity of a red grape wine flavonoid fraction against MCF-7 cells. Breast Cancer Res Treat 85: 65-79, 2004.

50. Ugartondo V, Mitjans M, Tourino S, Torres JL and Vinardell MP: Comparative antioxidant and cytotoxic effect of procyanidin fractions from grape and pine. Chem Res Toxicol 20: 1543-1548, 2007.

51. Miura T, Chiba M, Kasai K, et al: Apple procyanidins induce tumor cell apoptosis through mitochondrial pathway activation of caspase-3. Carcinogenesis 29: 585-593, 2008.

52. Leppert JT, Shvarts O, Kawaoka K, Lieberman R, Belldegrun AS and Pantuck AJ: Prevention of bladder cancer: A review. Eur Urol 49: 226-234, 2006.

53. Coates EM, Popa G, Gill CI, McCann MJ, McDougall GJ, Stewart D and Rowland I: Colon-available raspberry polyphenols exhibit anti-cancer effects on in vitro models of colon cancer. J Carcinog 6: 4, 2007.

54. Boivin D, Blanchette M, Barrette S, Moghrabi A and Beliveau R: Inhibition of cancer cell proliferation and suppression of TNFinduced activation of NFkappaB by edible berry juice. Anticancer Res 27: 937-948, 2007.

55. Weinberg WC and Denning MF: p21WAF1 control of epithelial cell cycle and cell fate. Crit Rev Oral Biol Med 13: 453-464, 2002 . 